\title{
High-resolution Simulations of Decadal Climate Variability Impacts on Spring and Winter Wheat Yields in the Missouri River Basin with the Soil and Water Assessment Tool (SWAT)
}

\section{Vikram Mehta ( $\square$ vikram@crces.org )}

CRCES: The Center for Research on the Changing Earth System https://orcid.org/0000-0003-3841034X

\section{Katherin Mendoza}

CRCES: The Center for Research on the Changing Earth System

Norman J. Rosenberg

CRCES: The Center for Research on the Changing Earth System

\section{Raghavan Srinivasan}

TAMU: Texas A\&M University College Station

\section{Research Article}

Keywords: Decadal climate variability, near-term climate change impacts, climate variability impacts, food security, crop modeling, adaptation to climate variability and change

Posted Date: May 10th, 2021

DOI: https://doi.org/10.21203/rs.3.rs-448886/v1

License: (c) (i) This work is licensed under a Creative Commons Attribution 4.0 International License. Read Full License

Version of Record: A version of this preprint was published at Climatic Change on October 1st, 2021. See the published version at https://doi.org/10.1007/s10584-021-03247-1. 


\section{Abstract}

The Missouri River Basin (MRB) encompasses one of the most important agricultural regions in the world. Three decadal climate variability (DCV) phenomena - the Pacific Decadal Oscillation (PDO), the tropical Atlantic sea surface temperature (SST) gradient variability (TAG), and the West Pacific Warm Pool (WPWP) variability - substantially influence hydro-meteorology and, consequently, spring and winter wheat yields in the MRB as indicated by data from 1961 to 2010. We applied the Soil and Water Assessment Tool (SWAT) to simulate DCV impacts on wheat yields in response to realistic values of the DCV indices in approximately 13,500 hydrologic unit areas covering the MRB. SWAT, driven by scenarios of past hydro-meteorological anomalies associated with positive and negative phases of the PDO and TAG, indicated major impacts on wheat yields, as much as $\pm 40 \%$ of the average in many locations, with smaller impacts of the WPWP variability. SWAT showed much larger wheat yield increases when the positive phase of the PDO and the negative phase of the TAG are superposed, and an equivalent decrease in yields when opposite phases of the two DCV phenomena are superposed. Thus, combined effects of DCV phenomena on wheat yields in the MRB can be dramatic with important consequences for food production and security. The usefulness of this inter-disciplinary study to farmers and other stakeholders for adapting MRB agriculture to DCV, and the applicability of the methodology to other agricultural regions are described. The results' implications for detection and attribution of climatic change impacts are also described.

\section{Introduction}

Multiyear to decadal hydrologic cycles (DHCs) - with dry and wet epochs - affect crop production, urban and rural water systems, pasture and range conditions, livestock production and health, infrastructure including river navigation, electricity generation, recreation, ecological integrity and, ultimately, regional and national economies (see, for example, Mehta et al. (2013a), Mehta (2017)). Droughts affect more people worldwide than does any other natural hazard (Wilhite 2000). Effects of multiyear to decadal floods and droughts are particularly dramatic in the agriculture sector, resulting each year in billions of dollars in crop losses around the world. In addition to the need for information in times of immediate flood and drought emergencies, planning for water, food, energy, and urban infrastructure development would benefit greatly from reliable information, were it available, on prospects for wet and dry epochs extending from a few seasons to a decade or longer. For example, an estimate of the monetary value of decadal climate variability (DCV) information to the agriculture sector in the Missouri River Basin (MRB) is that an accurate prediction of DCV phenomena one year in advance can be worth approximately $\$ 80$ million annually which could be derived from adaptation of the MRB agriculture sector to the predicted DCV information (Fernandez et al. 2016). A recent study found that the benefits of a perfect DCV phase forecast one year in advance to the entire U.S. agriculture enterprise can be worth $\$ 1.1$ billion (Rhodes and McCarl 2020). Extrapolated to the worldwide agriculture enterprise, monetary benefits can easily be many billions of dollars annually if optimized adaptation options, commensurate with likely impacts of the predicted DCV information, are implemented. But, skillful forecasts of this kind and 
adaptation options commensurate with them will require that the causes of DCV phenomena and their impacts be better understood.

Major DCV phenomena (Mehta 2020) are the Pacific Decadal Oscillation (PDO; Mantua et al. 1997)/the Interdecadal Pacific Oscillation (IPO; Power et al. 1999), the tropical Atlantic sea-surface temperature (SST) gradient variability (TAG; Houghton and Tourre 1992; Mehta and Delworth 1995; Mehta 1998), and the West Pacific Warm Pool SST variability (WPWP; Wang and Mehta 2008). These DCV phenomena are associated with the occurrence of DHCs on land (Mehta 1998; Nigam et al. 1999; Hidalgo 2004; McCabe et al. 2004; Meehl and Hu 2006; Seager et al. 2005; Schubert et al. 2009; Mehta et el. 2014; Mehta 2017).

While considerable progress has been made in understanding causes of DCV phenomena, simulation studies of impacts of DHCs associated with DCV phenomena on water availability and agriculture are in their infancy. Building on previous exploratory studies and interactions with stakeholders and policymakers in the MRB, the present study describes results of simulation experiments with high resolution Soil and Water Assessment Tool (SWAT) to estimate impacts of hydro-meteorological scenarios based on DCV phenomena on spring and winter wheat yields in the MRB.

This paper is organized as follows: Following this Introduction, associations between DCV and MRB wheat production is described in Sect. 1.1 and the rationale of the present study is described in Sect. 1.2. Then, brief descriptions of the climate and hydro-meteorological data, and the experimental design in Sect. 2; the experimental design is described in detail in Online Resource 2. Impacts of both individual and multiple DCV scenarios on winter and spring wheat yields are described in Sect. 3 . The results are discussed and conclusions are presented in Sect. 4. Implications of the results for adaptation to DCV and climate change impacts on MRB agriculture are also discussed in Sect. 4.

\subsection{Decadal Climate Variability and Wheat Production in the Missouri River Basin}

The MRB encompasses all or parts of ten U.S. states - Montana, North Dakota, South Dakota, Minnesota, Wyoming, Nebraska, lowa, Colorado, Kansas, and Missouri. The MRB is a very important agricultural region producing approximately $46 \%$ of U.S. wheat, $22 \%$ of its grain corn, and $34 \%$ of its cattle; approximately $90 \%$ of MRB cropland is entirely dependent on precipitation and is subject to vagaries of climate variability.

Large-scale wind, temperature, and precipitation anomalies associated with the PDO (see, for example, Ting and Wang (1997), McCabe et al. (2004), Mehta et al. (2011b), Mehta (2017)), the TAG (Schubert et al. 2009; Mehta et al. 2011b; Mehta 2017), and the WPWP variability (Wang and Mehta 2008; Mehta 2017) influence precipitation variability in the MRB. These DCV phenomena explain approximately 40$50 \%$ of the total precipitation, runoff, and streamflow variances within the Basin (Mehta 2017). Due to combined effects of DCV phenomena, the portion of the Basin experiencing severe to extreme droughts in the 20 th century ranged from $20-60 \%$ or more at interannual to decadal time scales (Mehta et al. 2013a). 
Portions of the Basin also experienced a multiyear to near-decadal drought during the first two decades of the 21 st century. The droughts have alternated with multiyear-to-decadal wet epochs (Mehta et al. 2016).

Figure 1 shows anomalous spring and winter wheat production estimates (million US tons) from 1961 to 2020, with respect to 60-year averages, from the U.S. Department of Agriculture's National Agricultural Statistics Service (NASS; https://www.nass.usda.gov/Quick_Stats/), along with the PDO and TAG indices. Correlation coefficients between each wheat production time series and the PDO index time series are approximately 0.5 (at least $95 \%$ significance) without smoothing and 0.65 after smoothing both time series. It is clear from Fig. 1 that - compared to the 60-year average - there are very substantial, multiyear to decadal variations in wheat production. The TAG index is less well correlated with MRB wheat production, but its associations with wheat production anomalies in some epochs are unmistakable. Not only climate variability, but also market forces and government policies influence crop production and, therefore, a perfect correlation cannot be expected with any of the climatic and other drivers of crop production.

\subsection{Rationale for the Present Study}

In an exploratory study, Mehta et al. (2012) used the Environmental Policy Integrated Climate (EPIC; Williams 1995) model to simulate per-hectare yields of non-irrigated corn, winter and spring wheat, and soybeans in response to DCV-associated hydro-meteorological anomalies in the MRB. Realistic values of the three DCV indices created substantial impacts on crop yields in these simulations. The results of the Mehta et al. (2012) study and another exploratory study of DCV impacts on water yields in the MRB with the SWAT model (Mehta et al. 2011b) were reported in several organized workshops to over 125 farmers, water managers, policymakers, and other stakeholders in the MRB. While the results were very interesting to these stakeholders and policymakers, they indicated (Mehta et al. 2013a) that, to be useful for planning and other purposes, climate and impacts information must be provided at the spatial and temporal resolutions required by each societal sector. The surface area of each watershed in our exploratory studies ranged from 800 to $13,000 \mathrm{sq}$. km, with an average of 4,500 sq. km. Thus, our studies included only $337,500 \mathrm{sq}$. $\mathrm{km}$ surface area out of the total of 1.3 million sq. $\mathrm{km}$ area of the MRB, and the exploratory studies used only minimally calibrated and validated SWAT and EPIC models. Therefore, in the present study, we used a very high resolution version of SWAT - now including a crop growth module and other improvements as described in Online Resource 1 and Daggupati et al. (2015). This resolution is approximately $12 \mathrm{~km}$ longitude $-12 \mathrm{~km}$ latitude, resulting in approximately 13,500 SWAT grid points encompassing the MRB. Employing the very high resolution SWAT allowed us to aggregate water and crop yields data at coarser resolution levels from local watersheds to the entire MRB as indicated by stakeholders and policymakers. During the 62 years (1949 to 2010) study period, the PDO, TAG, and WPWP indices were at or above their absolute average values in 32, 27, and 27 years, respectively. Therefore, simulating individual and simultaneous impacts of average amplitudes of these DCV phenomena not only provided insights into how DCV phenomena impact water and crop yields, but also allowed us to provide guidance to stakeholders and policymakers in the MRB on impacts of frequently 
occurring DCV phenomena. Additionally, simulating impacts of extreme (positive and negative maxima) amplitudes of these DCV phenomena during the study period allowed us to provide "best and worst case" scenarios to the stakeholders and policymakers. Impacts of DCV phenomena on water yields in these SWAT simulations were reported by Mehta et al. (2016). Impacts on spring and winter wheat yields are reported in this paper.

\section{Materials And Methods}

\subsection{Data}

Data on hydro-meteorological variables (HMVs) used in SWAT from 1950 to 1999 are from Maurer et al. (2002). The daily HMVs included precipitation rate, maximum and minimum air temperature, wind speed, and relative humidity -the last four at $2 \mathrm{~m}$ height. This data set is available for North America at a resolution of $0.125^{\circ} \times 0.125^{\circ}$ (approximately $12 \mathrm{~km}-12 \mathrm{~km}$ ) latitude - longitude grid spacing.

We used the Mantua et al. (1997) PDO index from 1961 to 2020. In the positive (negative) PDO phase, SSTs in the tropical-subtropical Pacific and along the west coasts of the Americas are warmer (cooler) than average, and SSTs in mid-latitude Pacific are cooler (warmer) than average. The TAG index (Houghton and Tourre 1992; Mehta 1998) was derived as the difference between monthly average SST anomalies in the tropical North Atlantic $\left(5.5^{\circ} \mathrm{N}\right.$ to $23.5^{\circ} \mathrm{N}$ and $15^{\circ} \mathrm{W}$ to $\left.57.5^{\circ} \mathrm{W}\right)$ and the tropical South Atlantic (Equator to $20^{\circ} \mathrm{S}$ and $10^{\circ} \mathrm{E}$ to $30^{\circ} \mathrm{W}$ ). When the TAG index is positive (negative), SST anomaly gradient points from the tropical South (North) Atlantic to the tropical North (South) Atlantic. The WPWP SST index (Mehta et al. 2019) was derived by averaging SST anomalies in the box $20^{\circ} \mathrm{S}$ to $20^{\circ} \mathrm{N}$ and $90^{\circ} \mathrm{E}$ to $180^{\circ}$. A positive (negative) WPWP index indicates warmer (cooler) than average SSTs in the WPWP region. While the PDO index time series did not have substantial linear trends during the study period, linear trends were removed from the time series of TAG and WPWP indices.

\subsection{Preparation of Idealized DCV-based Hydro- meteorological Scenarios}

As explained in Online Resource 1, the MRB was divided into three sub-regions (upper, middle, and lower) to simplify the modeling effort and increase computational speed. As listed in Table 1, 29 SWAT experiments were designed for each sub-region. To compare with the DCV scenario experiments, one climatology experiment was run at each local watershed in which SWAT was forced by monthly values of hydro-meteorological variables averaged over 1990 to 1999 as listed in Table 1. The method of preparation of hydro-meteorological scenarios is described in Online Resource 2. 
Table 1

Summary of 29 SWAT experiments in each sub-region of the Missouri River Basin.

$\begin{array}{lll}\begin{array}{l}\text { Experiment } \\ \text { Set }\end{array} & \text { DCV Phases/Combinations } & \begin{array}{l}\text { DCV Phenomenon Amplitude } \\ \text { (Between 1949 and 2010) }\end{array} \\ \begin{array}{l}\text { IDS-Average } \\ \text { (6 expts.) }\end{array} & \text { PDO+, PDO-, TAG+, TAG-, WPWP+, WPWP- } & \begin{array}{l}\text { Average amplitude of positive } \\ \text { or negative phase }\end{array} \\ \begin{array}{l}\text { CDS-Average } \\ (8 \text { expts.) }\end{array} & \begin{array}{l}\text { (PDO+, TAG+, WPWP+), (PDO-, TAG-, WPWP-), } \\ \text { (PDO+, TAG-, WPWP+), (PDO+, TAG-, WPWP-), }\end{array} & \begin{array}{l}\text { Average amplitude of positive } \\ \text { or negative phase }\end{array} \\ & \begin{array}{l}\text { (PDO-, TAG+, WPWP+), (PDO-, TAG+, WPWP-), } \\ \text { (PDO+, TAG+, WPWP-), (PDO-, TAG-, WPWP+) }\end{array} & \\ \begin{array}{l}\text { IDS-Extreme } \\ (6 \text { expts.) }\end{array} & \text { As in IDS-Average } & \begin{array}{l}\text { Maximum amplitude of } \\ \text { positive or negative phase }\end{array} \\ \begin{array}{l}\text { CDS-Extreme } \\ (8 \text { expts.) }\end{array} & \text { As in CDS-Average } & \text { Maximum amplitude of } \\ \begin{array}{l}\text { Base } \\ \text { climatology } \\ (1 \text { expt.) }\end{array} & - & \text { positive or negative phase }\end{array}$

To aid in interpretations of simulated wheat yields, we simulated annual-average spring and winter wheat yields in wet (1982 to 1986; relatively large magnitudes of $\mathrm{PDO}^{+}$and $\mathrm{TAG}^{-}$in Fig. 1) and dry (1987 to 1990; relatively small magnitudes of $\mathrm{PDO}^{-}$and $\mathrm{TAG}^{-}$in Fig. 1) periods. In these experiments, SWAT was forced by observed, daily HMV anomalies from Maurer et al. (2002). County-level spring and winter wheat yield estimates from the NASS for the two simulation periods were used to compare with simulated yields. Differences between the observed (NASS) and simulated spring and winter wheat yields were reasonably small. Perfect agreement should not be expected, however, as non-DCV related weather phenomena; and topography, soil type, antecedent soil moisture conditions, availability of nutrients, and vegetative cover, as well as market incentives and disincentives, also control wheat yields. The market factors were treated as uniform over the entire area and non-DCV related weather phenomena were not included in the experiments.

In figures in Sect. 3 showing impacts of various scenarios, each of the 12-digit watersheds in the MRB is represented by a symbol (square) placed at the center latitude - longitude of the watershed. Some symbols overlap due to the close proximity of the center points of neighboring watersheds, while others are spaced further apart, resulting in blank (white) space between locations. Figures in Sect. 3.1.2 and 3.2 have black dot marks at locations where differences in wheat yield have $95 \%$ statistical significance.

\section{Results And Discussion}

\subsection{Impacts of Individual Decadal Climate Variability Scenarios}




\subsubsection{Hydro-meteorological Anomalies Associated With Each Scenario}

Regression analyses indicated that substantial precipitation and temperature anomalies in the MRB are associated with both phases of the PDO as shown in Fig. 2 (Mehta et al. 2016). Figure 2a shows that precipitation anomalies associated with $\mathrm{PDO}^{+}$are generally positive in the MRB, except in the north central part of the Basin. Figure $2 \mathrm{~b}$ shows that precipitation anomalies associated with $\mathrm{PDO}^{-}$generally have the opposite signs. Largest precipitation anomalies associated with $\mathrm{PDO}^{+}$range from 3 to 5 $\mathrm{mm} /$ day and with $\mathrm{PDO}^{-}$from -3 to $-4 \mathrm{~mm} /$ day. Under $\mathrm{PDO}^{+}$, daily maximum temperature $\left(\mathrm{T}_{\max }\right.$ hereafter; Fig. 2c) is below average by 0.3 to $0.6^{\circ} \mathrm{C}$ except in small areas in Wyoming, Colorado, western Nebraska, and northern Kansas; most of Montana; and western North Dakota. Under PDO- conditions, $\mathrm{T}_{\max }$ (Fig. 2d) anomalies have generally opposite sign. Under $\mathrm{TAG}^{+}$, precipitation (Fig. 3a) is below average by 1 to $2 \mathrm{~mm}$ /day almost everywhere in the MRB. These precipitation changes are associated with $\mathrm{T}_{\max }$ increases from near 0 to $0.3^{\circ}$ (Fig. 3c), except for a few locations in central South Dakota, northern Wyoming, Nebraska, Kansas, and northeast Colorado where $T_{\max }$ is lower by a few tenths of a degree. In the $\mathrm{TAG}^{-}$phase, precipitation (Fig. 3b) and temperature (Fig. 3d) anomalies generally have the opposite signs. Precipitation and $\mathrm{T}_{\max }$ anomalies tend to be smaller in WPWP phases than under PDO or TAG phases, and generally differed in sign between its phases (not shown). Thus, all of the six individual DCV scenarios display some influence on the hydro-meteorology of the MRB, with PDO influences being the most substantial.

\subsubsection{Impacts on Spring and Winter Wheat Yields}

Simulated impacts of IDS-Average scenarios on spring and winter wheat are described in this section. Since wheat yield changes in $\mathrm{PDO}^{+}$and $\mathrm{TAG}^{-}$scenarios are largest and yield changes in their respective opposite phases generally have opposite signs, only the changes in these two scenarios are described here.

In the MRB, spring wheat is grown in northern Colorado, Wyoming, South and North Dakota, Montana, and a few isolated locations in Nebraska, lowa, and Minnesota. Spring wheat yield (Fig. 4a) increased by $10-30 \%$ of average yield in much of the southern part of the spring wheat region and in southwest Montana in response to HMV anomalies associated with $\mathrm{PDO}^{+}$(Figs. 2a and 2c), but not in eastern Montana, northern North Dakota, and individual locations in South Dakota, lowa, Missouri, and Wyoming where the yield decreased by $10-30 \%$. The average yield change aggregated over the entire spring wheat area in both phases of the PDO was within $\pm 20 \%$ of average yield which is a substantial impact considering that the MRB produces a very large portion of the total US wheat production. In response to HMV anomalies associated with TAG $^{-}$(Figs. 3b and 3d), spring wheat yield (Fig. 4b) decreased by 10$20 \%$ in large areas of western Montana, eastern North and South Dakota, and a few isolated areas in Wyoming and lowa. Yield increased by approximately $10-20 \%$ in southern Montana, western North and 
South Dakota, and in small areas in Wyoming, southeast Montana, Nebraska, lowa, and Colorado. In WPWP $^{+}$phase (not shown), yields decreased by $10-30 \%$ in the central part of the spring wheat area in the MRB and increased by $10-20 \%$ in western Montana, almost all of South Dakota, central and southern Wyoming, western Nebraska, western lowa, and western Missouri.

Winter wheat is grown in all states of the MRB. In PDO+ (Fig. 4c), there were 10-30\% increases in winter wheat yield in central MRB, western lowa, southwestern Montana, and northern Kansas; and 30-40\% yield increases in small pockets in northern and southern South Dakota, along the Nebraska - Kansas border, and in northern Missouri. Elsewhere in the MRB, yields decreased by 10-20\% - mainly in Montana and North Dakota, and small pockets in Kansas, lowa, and Missouri. Yields increased in TAG $^{-}$(Fig. 4d) almost everywhere in the MRB, except in central and western Montana, eastern North and South Dakota, and isolated pockets in Wyoming, Colorado, Nebraska, and Kansas where yields decreased by about $10 \%$. Winter wheat yield increased under the WPWP ${ }^{+}$phase (not shown) in Kansas, Missouri, southeastern Wyoming, southern and central South Dakota, and isolated areas in Montana and North Dakota. Winter wheat yield decreased in the WPWP ${ }^{+}$phase in southeast Montana, central and southern North Dakota, around the Colorado - Nebraska - Kansas border, and in isolated areas in Wyoming and eastern North Dakota.

\subsection{Impacts of Multiple Decadal Climate Variability Scenarios}

\subsubsection{Hydro-meteorological Anomalies Associated With Each Scenario}

In the second set of SWAT experiments, titled CDS-Average, we simulated responses of spring and winter wheat yields to scenarios of three DCV phenomena occurring simultaneously. There are eight combinations of three DCV phenomena as shown in Table 1 and explained in Sect. 2.2 and Online Resource 2. Precipitation and temperature anomalies at the average amplitude associated with each of the six IDS-Average scenarios (Sect. 3.1.1) were superposed into eight CDS-Average scenarios according to Tables 1 and 2. The combined precipitation and temperature anomalies were then superimposed on their respective, monthly 10-year average values and the total precipitation and temperature were used as input to SWAT. All eight of the CDS-Average scenarios impact hydro-meteorology and wheat yields in the Basin, with $\left(\mathrm{PDO}^{+}, \mathrm{TAG}^{-}, \mathrm{WPWP}^{+/-}\right)$and $\left(\mathrm{PDO}^{-}, \mathrm{TAG}^{+}, \mathrm{WPWP}^{+/-}\right)$combinations making the largest impacts. $\mathrm{PDO}^{+}$and $\mathrm{TAG}^{-}$phases reinforce each other to produce generally wetter and cooler conditions, whereas $\mathrm{PDO}^{-}$and $\mathrm{TAG}^{+}$phases reinforce each other to produce generally dryer and warmer conditions (see Figs. 2 and 3). Overall, both phases of the WPWP impact hydro-meteorology of the Basin as a whole to a lesser extent than PDO and TAG phases as mentioned in Sect. 3.1.1. 
Table 2

Monthly Amplitudes of DCV Phenomena in Each Scenario.

\begin{tabular}{|llllllllll|}
\hline & PDO & & & TAG & \multicolumn{5}{c|}{ WPWP } \\
\hline MON & AVE & MAX & MIN & AVE & MAX & MIN & AVE & MAX & MIN \\
JAN & 0.69 & 1.78 & -1.26 & 0.25 & 0.59 & -0.83 & 0.08 & 0.15 & -0.27 \\
FEB & 0.74 & 1.68 & -1.51 & 0.30 & 0.74 & -0.92 & 0.08 & 0.17 & -0.22 \\
MAR & 0.76 & 1.82 & -1.26 & 0.31 & 0.89 & -0.75 & 0.08 & 0.19 & -0.22 \\
\hline APR & 0.70 & 1.41 & -1.49 & 0.33 & 0.85 & -0.90 & 0.07 & 0.19 & -0.17 \\
MAY & 0.78 & 1.93 & -1.50 & 0.32 & 0.88 & -1.02 & 0.06 & 0.17 & -0.14 \\
\hline JUN & 0.61 & 1.76 & -1.34 & 0.27 & 0.62 & -0.83 & 0.06 & 0.12 & -0.19 \\
\hline JUL & 0.67 & 1.71 & -1.18 & 0.20 & 0.36 & -0.68 & 0.06 & 0.12 & -0.15 \\
\hline AUG & 0.56 & 1.14 & -0.98 & 0.18 & 0.36 & -0.56 & 0.06 & 0.14 & -0.15 \\
\hline SEP & 0.48 & 1.19 & -1.01 & 0.18 & 0.32 & -0.57 & 0.07 & 0.18 & -0.17 \\
\hline OCT & 0.53 & 1.12 & -0.92 & 0.20 & 0.34 & -0.62 & 0.07 & 0.19 & -0.21 \\
\hline NOV & 0.44 & 1.16 & -0.86 & 0.19 & 0.35 & -0.55 & 0.07 & 0.16 & -0.21 \\
\hline DEC & 0.46 & 1.64 & -0.97 & 0.21 & 0.57 & -0.61 & 0.07 & 0.16 & -0.21 \\
\hline
\end{tabular}

\subsubsection{Impacts on Spring and Winter Wheat Yields}

Since combinations of opposite phases of PDO and TAG produce maximal impact on wheat yields, their effects in CDS-Average scenarios on spring and winter wheat yields are described here. As Fig. 5a shows, with WPWP in its positive phase, the impact of the $\left(\mathrm{PDO}^{+}, \mathrm{TAG}^{-}\right)$scenario on spring wheat yield is greater than that of either of the DCV phenomena alone. Effects of the superposition of PDO ${ }^{+}$(Fig. 4a) and TAG ${ }^{-}$ (Fig. 4b) phases are most evident in the central part of the spring wheat growing region; that is, in western North and South Dakota, eastern Wyoming, and southwestern Montana. Overall, the combined effects were substantially different in this CDS-Average scenario than in IDS-Average PDO ${ }^{+}$(Fig. 4a) or $\mathrm{TAG}^{-}$ (Fig. 4b) scenarios alone. This is also true in the $\left(\mathrm{PDO}^{-}, \mathrm{TAG}^{+}, \mathrm{WPWP}^{+}\right.$) scenario (Fig. 5b) in which the yield anomalies are generally opposite in sign to those in Fig. $5 \mathrm{a}$. In both its phases, WPWP made substantial impacts in eastern South Dakota, and eastern and western Montana.

As discussed above for spring wheat yield, maximum impacts on winter wheat also occurred under $\left(\mathrm{PDO}^{+}, \mathrm{TAG}^{-}\right)$and $\left(\mathrm{PDO}^{-}, \mathrm{TAG}^{+}\right) \mathrm{CDS}$-Average scenarios for the same WPWP phase. Since the PDO ${ }^{+}$ (Fig. 4c) and TAG ${ }^{-}$(Fig. 4d) phases cause increases in winter wheat yields over most of the MRB, their superposition results in an even larger area of the MRB with yield increases in the ( $\left.\mathrm{PDO}^{+}, \mathrm{TAG}^{-}, \mathrm{WPWP}^{+}\right)$ CDS-Average scenario (Fig. 5c). The superposition effects are most evident in the southern half of the 
MRB and western North Dakota. In northern Montana, yields decrease in both $\mathrm{PDO}^{+}$and $\mathrm{TAG}^{-}$phases and their superposition enlarges this area. The combination also results in pockets of greater than $40 \%$ yield increases in southern Montana, in South Dakota, and along the eastern Kansas - Nebraska border, as well as in northern Missouri. In the ( $\mathrm{PDO}^{-}, \mathrm{TAG}^{+}, \mathrm{WPWP}^{+}$) CDS-Average scenario (Fig. $5 \mathrm{~d}$ ), the effects of superposition of the $\mathrm{PDO}^{-}$and $\mathrm{TAG}^{+}$scenarios are generally opposite to those in the ( $\mathrm{PDO}^{+}, \mathrm{TAG}^{-}$, WPWP ${ }^{+}$) scenario, including in producing pockets of greater than $40 \%$ yield decreases in several MRB states.

In order to understand how the hydro-meteorological anomalies associated with DCV scenarios influence wheat yields, we analyzed water and temperature stresses under $\mathrm{CDS}$-Average $\left(\mathrm{PDO}^{+}, \mathrm{TAG}^{-}, \mathrm{WPWP}^{+}\right)$and $\left(\mathrm{PDO}^{-}, \mathrm{TAG}^{+}, \mathrm{WPWP}^{+}\right)$scenarios in four 4-digit sub-basins for winter wheat in Montana, Wyoming, northern Nebraska, and northern Missouri-southern lowa; and three 4-digit sub-basins for spring wheat in northern Montana, North Dakota-South Dakota, and South Dakota-Minnesota-lowa. These stresses were calculated by SWAT during each simulation experiment. For winter wheat, we found that the 4-digit subbasins in the northern part of the Basin have higher water and temperature stresses compared to the southern part. In both scenarios, temperature stress is greater than water stress in all except one subbasins. We also found that wheat yields are much more sensitive to water stress than temperature stress. Those 12-digit sub-basins within 4-digit sub-basins with lower water stress have higher winter wheat yields. Since winter and spring wheat are cold season crops, it is expected that they are not sensitive to cold temperatures as confirmed by the SWAT simulations. For spring wheat simulations, 4-digit subbasins in the northern part of the MRB have higher stresses compared to the southern part. Also, spring wheat yields are more sensitive than winter wheat yields to water stress compared to temperature stress. Interestingly, water stress is greater than temperature stress in both scenarios for spring wheat unlike winter wheat where the opposite behavior is evident. Furthermore, the number of stress days are also relatively lower for spring wheat compared to winter wheat in both scenarios.

\subsection{Impacts of Extreme Magnitudes of Decadal Climate Variability Phenomena}

The results described in Sect. 3.1 and 3.2 were obtained with single-DCV (IDS-Average) and multiple-DCV (CDS-Average) scenarios using average magnitudes of observed DCV indices that have occurred between 1949 and 2010. SWAT runs were also made with DCV scenarios encompassing extreme positive and negative magnitudes of PDO, TAG, and WPWP indices observed during that period; these scenarios are referred to as IDS-Extremes and CDS-Extremes in Table 1. Results of these SWAT experiments are briefly described in this section, but are not shown.

In single DCV scenarios with extreme magnitudes (IDS-Extremes), the spatial distribution of impacts on spring and winter wheat yields was generally the same as appears in the average magnitude single DCV scenarios (IDS-Average) shown in Fig. 4. Wheat yields in the IDS-Extremes scenarios increased by approximately 10-20\%. In multiple DCV scenarios (CDS-Extremes), however, the impacts of extreme DCV magnitudes were magnified by superposition of same-sign anomalies. As before, $\left(\mathrm{PDO}^{+}, \mathrm{TAG}^{-}\right)$and 
$\left(\mathrm{PDO}^{-}, \mathrm{TAG}^{+}\right.$) scenarios, coupled with either WPWP phase (but same WPWP phase in both combinations), led to the maximum impacts on wheat yields. While the overall pattern of response to the extremeamplitude scenarios remained the same as in the average-amplitude scenario, the magnitudes of yield changes in $\left(\mathrm{PDO}^{+}, \mathrm{TAG}^{-}, \mathrm{WPWP}^{+}\right)$and $\left(\mathrm{PDO}^{-}, \mathrm{TAG}^{+}, \mathrm{WPWP}^{+}\right)$scenario are $20-30 \%$ greater. The number of pockets of greater than $40 \%$ yield changes also increased in the CDS-Extremes scenarios.

In the U.S. Geological Survey nomenclature, there are 29 4-digit sub-basins in the MRB. SWAT-simulated wheat yields and total area of each sub-basin where spring and winter wheat are grown were used to calculate total production in each sub-basin. The total production numbers must be interpreted with the caveat that in these 29 simulation experiments with SWAT, the planted and harvested areas of spring and winter wheat were the same in all experiments which would not be true in the real world. Figure 6 shows the average production (in thousand metric tons) at locations where the difference between two scenarios $\left(\left(\mathrm{PDO}^{+}, \mathrm{TAG}^{-}, \mathrm{WPWP}^{+}\right)\right.$and $\left.\left(\mathrm{PDO}^{-}, \mathrm{TAG}^{+}, \mathrm{WPWP}^{+}\right)\right)$is $95 \%$ significant, and difference in production (percent of average production) for each 4-digit sub-basin; results for both CDS-Average (Fig. 6a) and CDS-Extreme (Fig. 6b) scenarios are shown in Fig. 6. For the CDS-Average scenarios, there are nine sub-basins where the difference in winter wheat production between the two multi-DCV scenarios is greater than $10 \%$ of the average production, with the difference in one sub-basin in Montana and Wyoming almost 50\% and the difference in one sub-basin in lowa and Missouri (1028) almost 30\%. Consistently with the winter wheat yield results shown in Fig. 5, there is greater production in the upper part of the MRB in the $\left(\mathrm{PDO}^{-}, \mathrm{TAG}^{+}, \mathrm{WPWP}^{+}\right)$scenario compared to the $\left(\mathrm{PDO}^{+}, \mathrm{TAG}^{-}, \mathrm{WPWP}^{+}\right)$scenario, whereas there is greater production in the middle and lower parts of the MRB in the latter scenario. In the CDS-Extremes scenarios in Fig. 6, 21 out of 29 sub-basins show greater than 10\% differences between the two multi-DCV scenarios; with 12 sub-basins showing greater than $20 \%$ differences, and two subbasins (mentioned above) showing $72 \%$ and almost $60 \%$ differences, respectively.

The corresponding production estimates at locations of 95\% significance for spring wheat indicate (not shown) that there are greater than $10 \%$ differences between the two multi-DCV CDS-Average scenarios in four 4-digit sub-basins. In the CDS-Extremes scenarios for spring wheat, the differences are greater than $10 \%$ in 19 sub-basins, with greater than $20 \%$ differences in five sub-basins.

Thus, these results show that extreme magnitudes and opposite phases of PDO and TAG, combined with the same WPWP phase, can lead to devastating wheat yield decreases in the MRB at times and abundant wheat yields at others. As mentioned earlier, however, the real-world differences in wheat production in various DCV combinations would depend not only on DCV impacts on per-hectare yields but also on planted and harvested areas.

\section{Discussion And Conclusions}

We conducted experiments with a state-of-the-art, high-resolution version of SWAT - calibrated and validated for the MRB - to estimate impacts of the PDO, TAG, and WPWP variabilities on spring and winter wheat yields. Impacts of positive and negative phases of individual DCV phenomena as well as of 
combinations of the three DCV phenomena were simulated by forcing SWAT at approximately 13,500 locations ( grid spacing of $12 \mathrm{~km}$ longitude - $12 \mathrm{~km}$ latitude) with idealized hydro-meteorological scenarios associated with the DCV phenomena. Experiments were conducted with average magnitudes and with extreme magnitudes of indices of the three DCV phenomena as observed from 1949 to 2010. Major results/products of this study are:

$\mathrm{a} \triangle \mathrm{A}$ methodology sensitive enough to detect effects of average magnitudes of major $\mathrm{DCV}$ phenomena on crop yields from the local (12-digit basin) to the regional (Major Water Resource Region; 2-digit basin) scale has been developed.

a $₫ A$ All six individual DCV scenarios at their average magnitudes affect hydro-meteorology and wheat yields in the MRB, with PDO making the largest impacts followed by TAG and then WPWP. Impacts of $\left(\mathrm{PDO}^{+}, \mathrm{TAG}^{-}\right)$and $\left(\mathrm{PDO}^{-}, \mathrm{TAG}^{+}\right)$combinations on spring and winter wheat yields are substantially stronger (up to $30-40 \%$ or more with respect to recent average yields) than those of either DCV phenomena alone. All eight multiple-DCV scenarios affect hydro-meteorology and wheat yields of the Basin, with (PDO+, TAG-, WPWP ${ }^{+/-}$) and (PDO, TAG $^{+}$, WPWP ${ }^{+/}$) scenarios having the maximum overall impacts. Extreme magnitudes of the three DCV phenomena are associated with severe to extreme impacts on wheat yields in the MRB.

aV Local conditions appear to influence wheat yield responses to DCV phenomena in South Dakota, northern Kansas, northern Missouri, and Montana under extreme scenarios.

A comparison of simulated impacts of idealized DCV scenarios on spring and winter wheat yields described in this paper - with our exploratory study (Mehta et al., 2012) shows that while the overall spatial patterns of impacts of individual DCV phenomena on wheat yields in the MRB are generally similar, impacts are much larger in magnitude at some locations and in some 4-digit basins in the present study. This difference may be due largely to the much higher resolution employed in the present study, and to the meticulous calibration and validation of the SWAT model. There are 180 times more samples in the present study (approximately 13,500 locations), so analyses results are much more accurate and reliable compared to the exploratory study where there were only 75 locations in the entire MRB. Another major difference is that the exploratory study did not simulate impacts of multiple, simultaneous DCV phenomena on wheat yields. As shown by this study, impacts of $\left(\mathrm{PDO}^{+}, \mathrm{TAG}^{-}\right)$and $\left(\mathrm{PDO}-\mathrm{TAG}^{+}\right)$ combinations can be much larger in magnitude than those of an individual DCV phenomenon at its average amplitude, the former combination potentially causing major periods of abundant wheat yields and the latter devastating decreases in wheat yields. Instances of associations between larger spring and winter wheat productions and relatively large-magnitude $\left(\mathrm{PDO}^{+}, \mathrm{TAG}^{-}\right)$combination can be seen in Figure 1 in the 1990 to 1998 and 2013 to 2016 periods; instances of associations between relatively smaller spring wheat production and relatively large-magnitude $\left(\mathrm{PDO}^{-}, \mathrm{TAG}^{+}\right)$combination can be seen in Figure 1 in the 1998 to 2012 period. Of course, the biggest difference between this study and our exploratory study is the usability of the present results by stakeholders and policymakers as explained in Section 1.2 . 
So, how can stakeholders and policymakers apply results of this study to adapt to DCV impacts? As mentioned briefly in section 1.2, Mehta et al. (2013a) reported the usefulness of DCV and impacts information as indicated by over 125 stakeholders and policymakers in the MRB. Since the various ways such information can be useful to agriculture and other sectors is described in detail by Mehta et al. (2013a), only the highlights of the usefulness for the agriculture sector are mentioned here. Decadal climate outlooks and their possible impacts on agriculture, as simulated in the present study, can be useful for (1) selecting crops and cultivars, (2) changes in crop rotation or tillage practices, (3) irrigation planning, (4) purchasing crop insurance, (5) decisions between dryland and irrigated crops, (6) decisions between food crops and biofuel crops which are more drought-resistant, (7) investments in irrigation systems, and (8) assessing viability of operations if a multiyear to decadal dry/wet epoch is predicted. As mentioned in the Introduction (section 1), Fernandez et al. (2016) and Rhodes and McCarl (2020) estimated that the monetary value of such adaptation options to MRB agriculture and U.S. agriculture, respectively, would be very substantial. Since the MRB produces a major portion of the wheat produced in the U.S., impacts of multiyear to decadal dry/wet epochs, as simulated in the present study, can make very substantial impacts on U.S. wheat prices and exports, thereby impacting national and global food security. Therefore, DCV and impacts predictions can also be very useful in adapting national and global food security to multiyear to decadal dry/wet epochs.

Because the three DCV phenomena whose impacts on non-irrigated wheat yields were modeled in this study are known to influence climate and hydro-meteorology in other parts of the world as well (as do other DCV phenomena not addressed in this study), our methodology should also be applicable to other non-irrigated agricultural regions. It is certainly possible that the evolution of major DCV phenomena will be forecast with some skill in the foreseeable future (Meehl et al. 2021). When this happens, it may become possible, with SWAT and other well-validated land use-hydrology-crop models, to forecast DCV phenomena's multiyear to decadal impacts on water and crop yields in those regions known to be affected by DCV.

Our results show that the three DCV phenomena considered in this study, if they occur individually, can significantly impact wheat yields in the MRB. As these DCV phenomena can persist in either of their phases for a few years to a decade or longer, and as the simultaneous correlation among them is negligibly small, their combined and cumulative effects on the MRB hydro-meteorology and wheat yields should be sufficient to impact not only the agriculture sector but also transportation, irrigation, and other water-related sectors as shown by Mehta et al. (2016) by analyses of the same SWAT experiments described here; and local, state, and perhaps even national economies. These results also imply important consequences of these impacts on crop yields to feedbacks to the climate system via water vapor, heat, momentum, and carbon fluxes; and for nutrient content of run-off from wheat fields into streams/rivers and thereby on water quality for other sectors.

Results of the present study are also very relevant and applicable to climatic change impacts. It is well-known (see, for example, Henley and King (2017)) that natural DCV confounds the detection and attribution of anthropogenic climatic change. Similarly, DCV impacts on yields and productions of wheat 
and other crops would also confound the detection and attribution of future climatic change impacts on agriculture. For example, approximately one half-cycle of DCV impacts can exacerbate climatic change impacts and the other half-cycle can reduce climatic change impacts substantially. Therefore, it is very important for any plan to adapt to changing climate to include realistic simulations and predictions of DCV impacts to avoid misleading conclusions and actions. This study and Mehta et al. (2016) offer insights to past, current, and future weather-driven crop yield and water yield variability at multiyear to decadal timescales that may aid in projection of long-term climatic change effects on both. Most research on crop yields and water availability under climatic change assumes a uni-directional change (for example, increasingly hotter and drier) occurring at a reasonably accurate projectable/predictable rate driven by greenhouse gas emissions. But, future climate scenarios based on past data of natural DHCs, driven by DCV phenomena, provide the natural complexity and realism of seasonal and annual weather variability within an epoch. It is from documentation of such epochs' history and assessment of their impacts that climatic change projections/predictions can be made more complex and realistic, and hence, more useful. In addition, impacts of DCV phenomena on crop yields are qualitatively and quantitatively different from impacts of seasonal to interannual climate variability. For example, multiyear to decadal droughts associated with DCV can even induce farmers to consider selling their lands and quit farming as a serious option which would be similar to farmers' future decisions to quit farming if local climate is projected to become perpetually drought-like. Adaptation options based on simulations of DCV impacts on crop yields, as described in this paper and in Mehta et al. (2013a), can also be used to develop adaptation options for a future, climatic change-driven, perpetual drought-like situation. Finally, rigorous testing of SWAT and other such hydrology-crop models, with respect to past dry/wet epochs and crop yield data, as described here can inspire high confidence in such models' use for simulating/projecting climatic change impacts on water and agriculture.

\section{Declarations}

Funding This research was supported by the U.S. Department of Agriculture-National Institute of Food and Agriculture under Grant 2011-67003-30213 in the National Science Foundation-U.S. Department of Agriculture-U.S. Department of Energy Earth System Modelling Program and by National Oceanic and Atmospheric Administration-Climate Program Office-Sectoral Applications Research Program Grant NA120AR4310097.

Conflicts of interest/Competing interests Authors have no relevant financial or non-financial interests to disclose.

Availability of data and material Data used in this study are available from the corresponding author upon request.

Code availability The version of the SWAT model, calibrated and validated for the MRB, used in this study is available from the corresponding author upon request. 
Authors' contributions All authors contributed to the study design. SWAT model preparation, necessary meteorological and other data collection, and analysis were performed by K. Mendoza and V. Mehta. The first draft of the manuscript was written by V. Mehta and all authors commented on previous versions of the manuscript. All authors read and approved the final manuscript.

\section{Figures}

\section{Spring Wheat Production Anomalies and PDO}

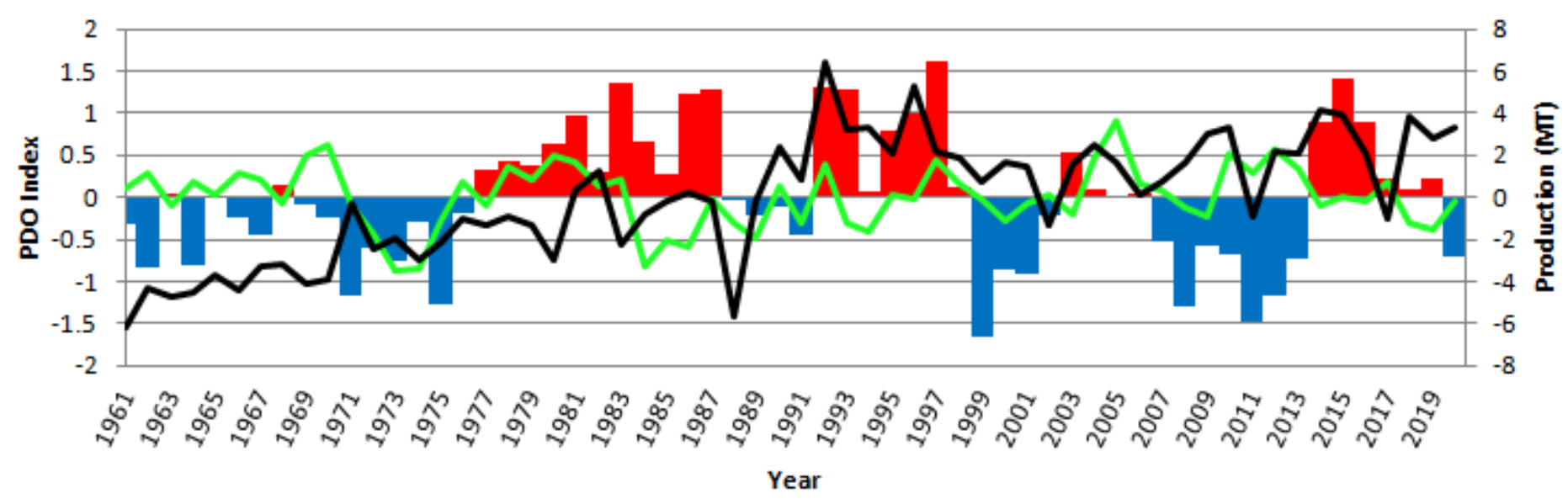

Winter Wheat Production Anomalies and PDO

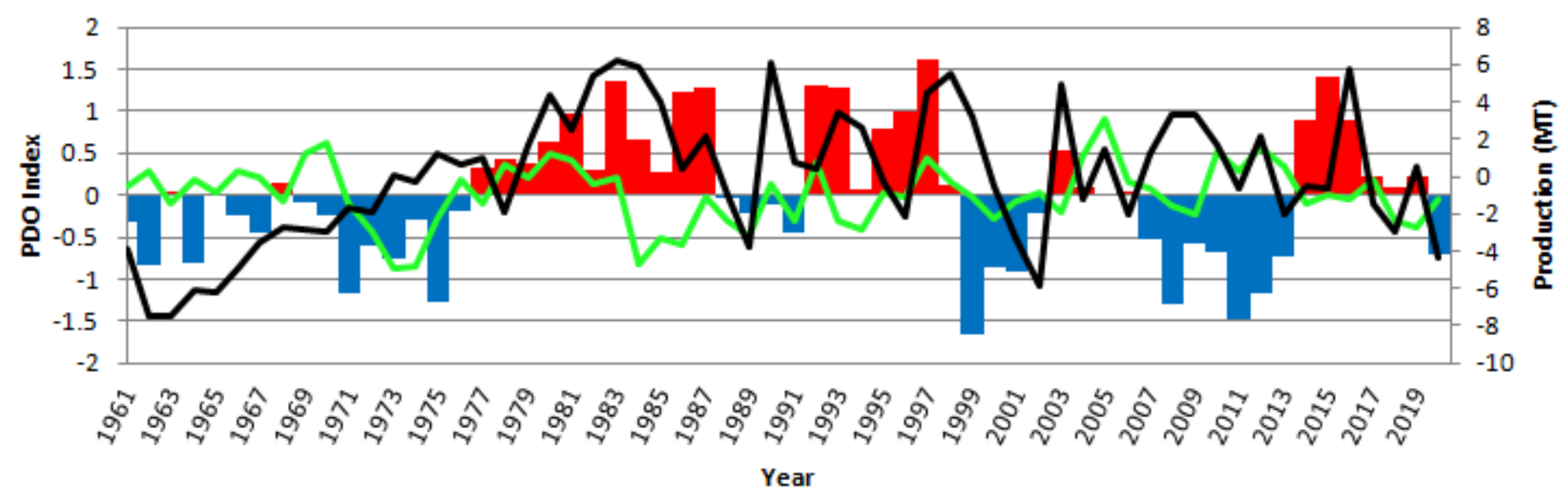

Figure 1

Wheat production anomalies with respect to average values for spring and winter wheat time series (black line; million tons; right scale) aggregated in the MRB, and the PDO index (bars; left scale) and the TAG index (green line; left scale) from 1961 to 2020. The average productions in this period were 8.6 million tons and 17.7 million tons, respectively, for spring wheat and winter wheat. 
PDO $^{+}$
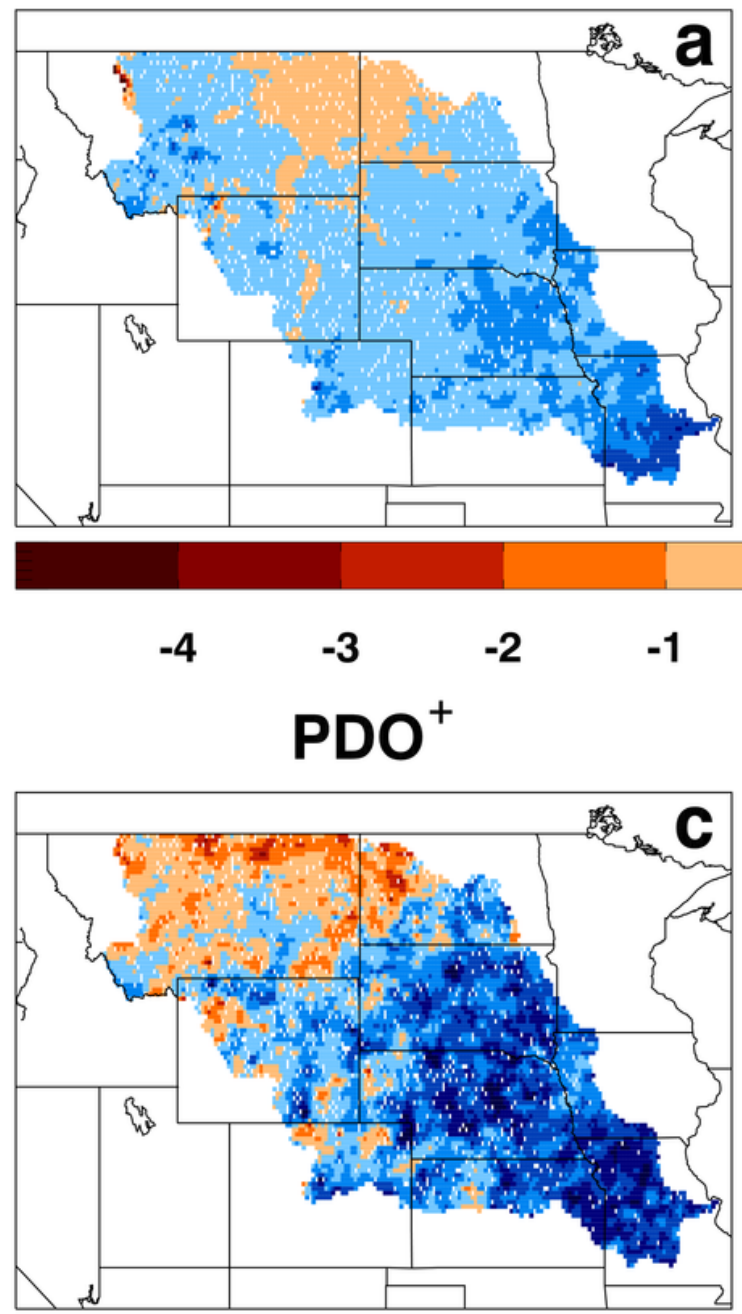

$\begin{array}{llll}-0.6 & -0.45 & -0.3 & -0.15\end{array}$
PDO

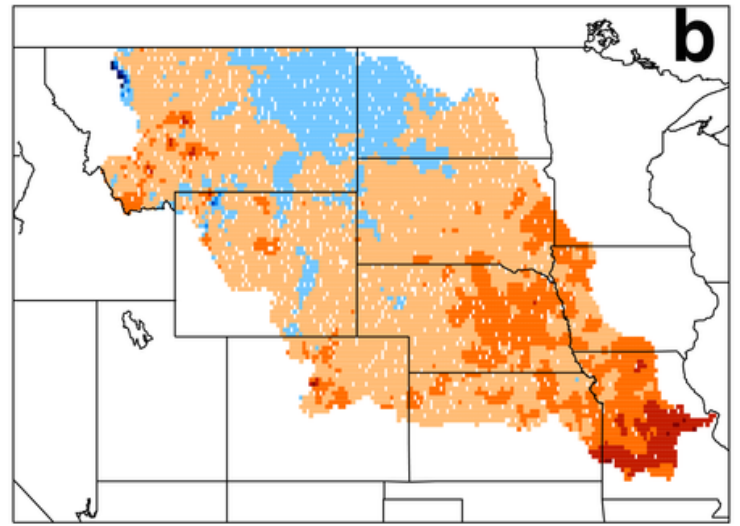

$0 \quad 1$

2

3

4

PDO

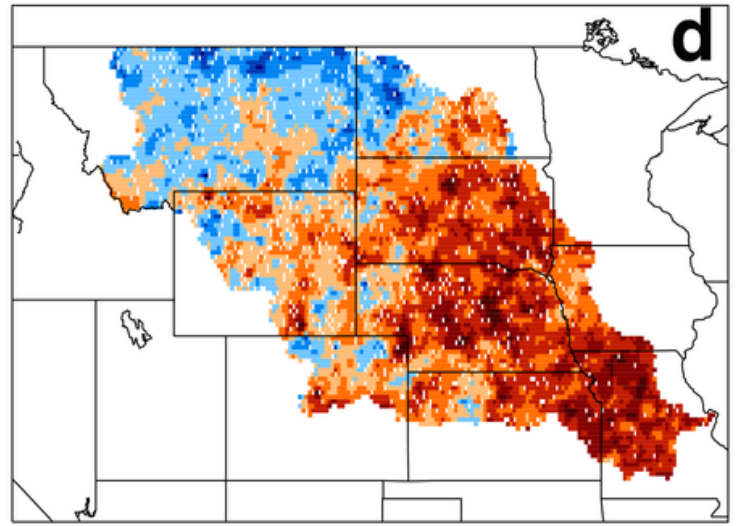

$\begin{array}{lll}0.15 & 0.3 & 0.45\end{array}$

0.6

Figure 2

Annual-average precipitation $\left(\mathrm{mm} /\right.$ day) and daily maximum temperature $\left({ }^{\circ} \mathrm{C}\right)$ anomalies associated with (a) PDO+, precipitation, (b) PDO-, precipitation, (c) PDO+, temperature, and (d) PDO-, temperature. 
TAG $^{+}$
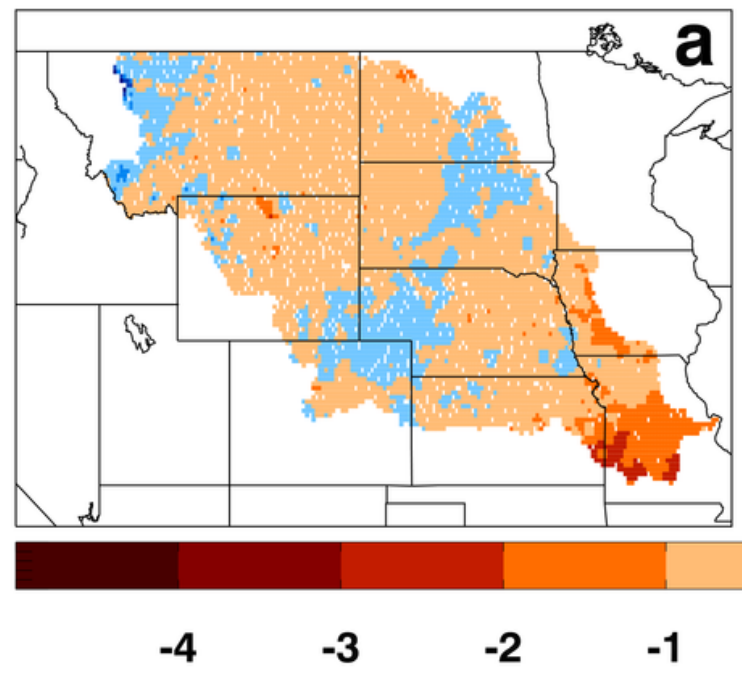

TAG $^{+}$
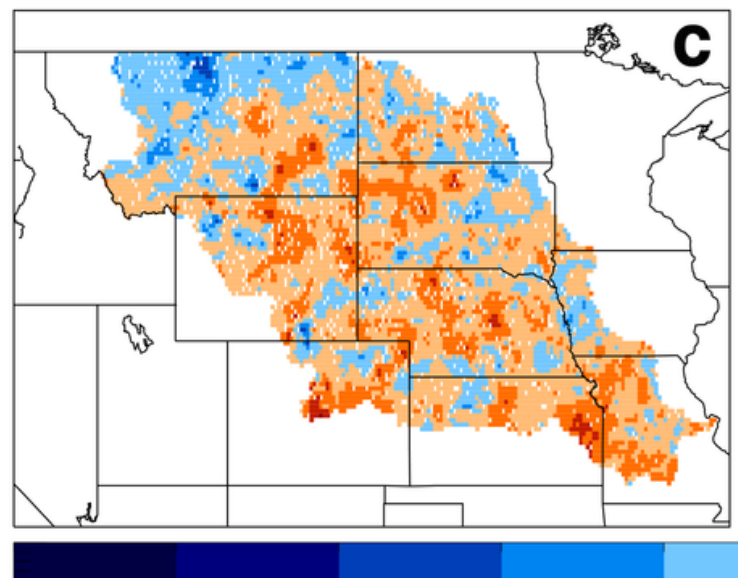

$\begin{array}{llll}-0.6 & -0.45 & -0.3 & -0.15\end{array}$
TAG
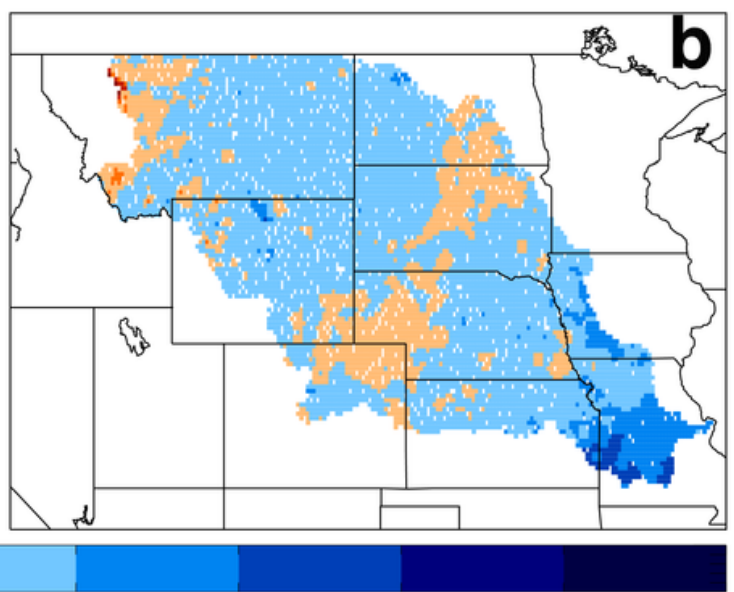

$0 \quad 1$

2

3

4

TAG $^{-}$

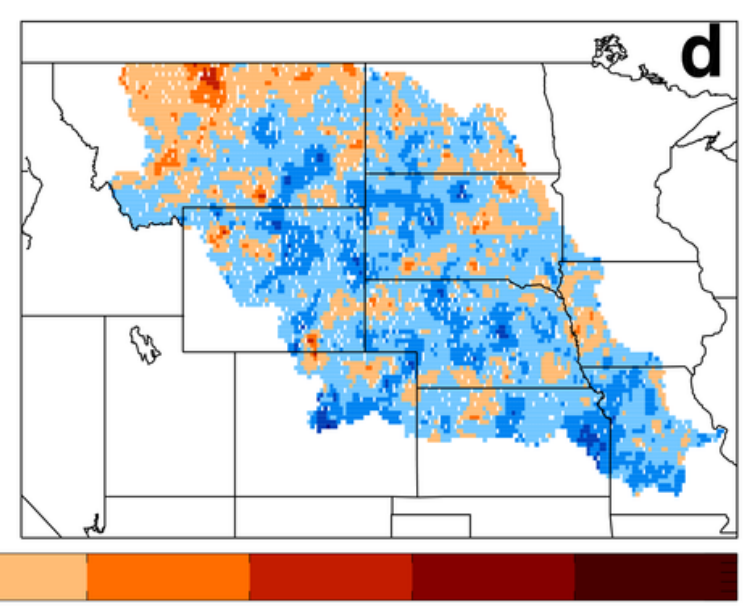

$\begin{array}{llll}0.15 & 0.3 & 0.45 & 0.6\end{array}$

Figure 3

Annual-average precipitation ( $\mathrm{mm} /$ day) and daily maximum temperature $\left({ }^{\circ} \mathrm{C}\right)$ anomalies associated with (a) TAG+, precipitation, (b) TAG-, precipitation, (c) TAG+, temperature, and (d) TAG-, temperature. 

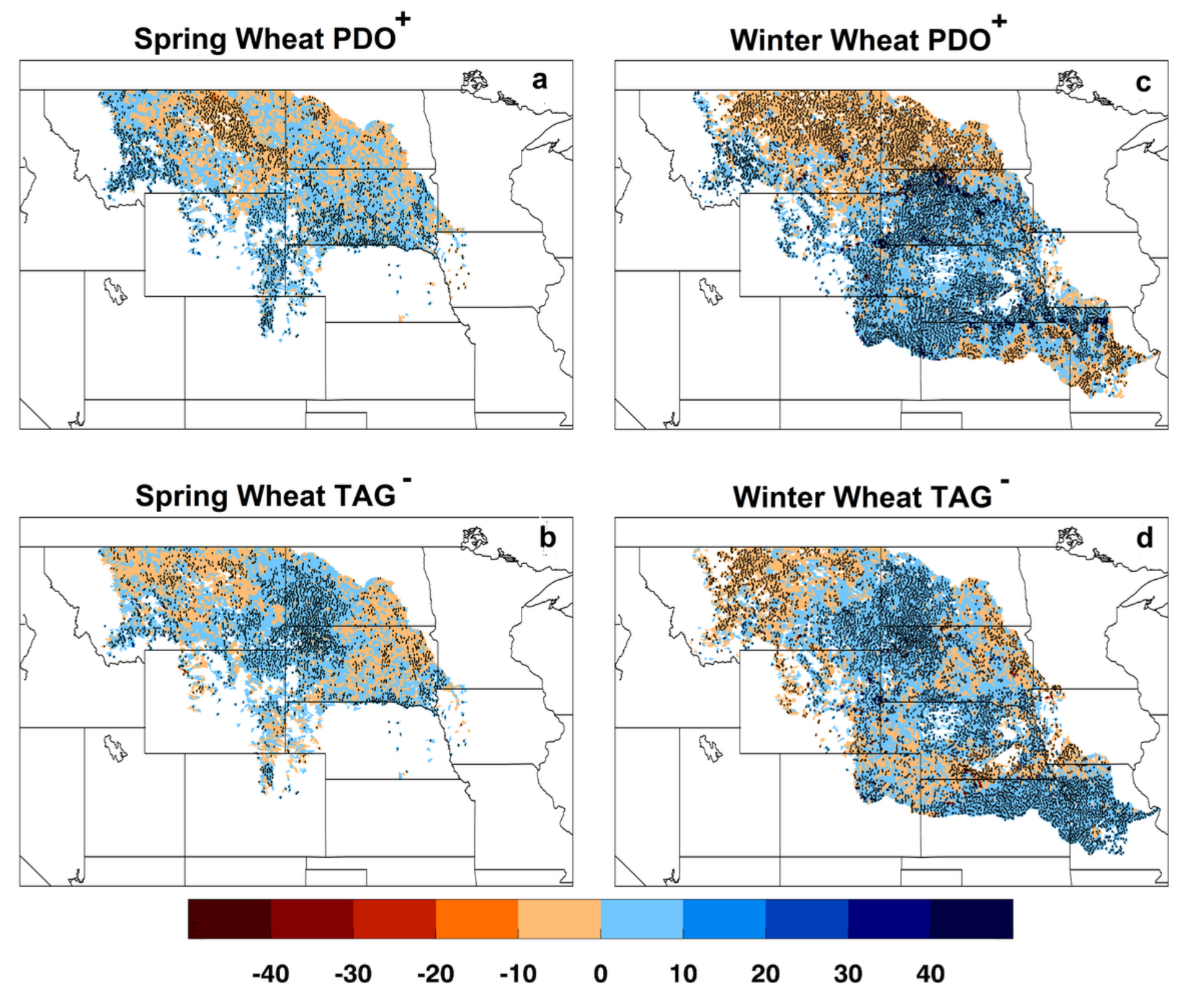

Figure 4

Figure 4 legend not available with this version. 
Spring Wheat $\mathrm{P}+\mathrm{T}-\mathrm{W}+$

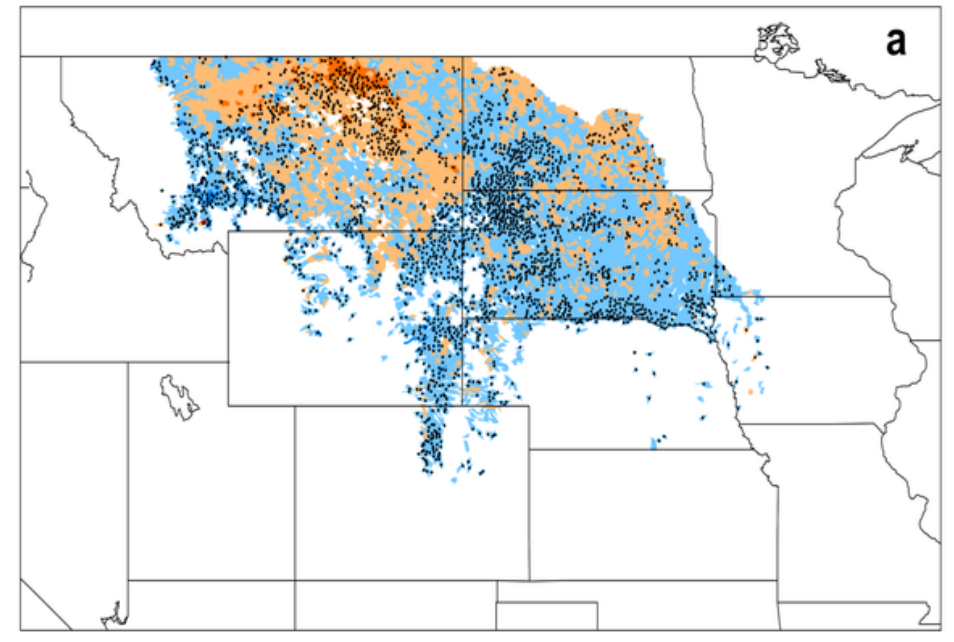

Spring Wheat P-T+W+

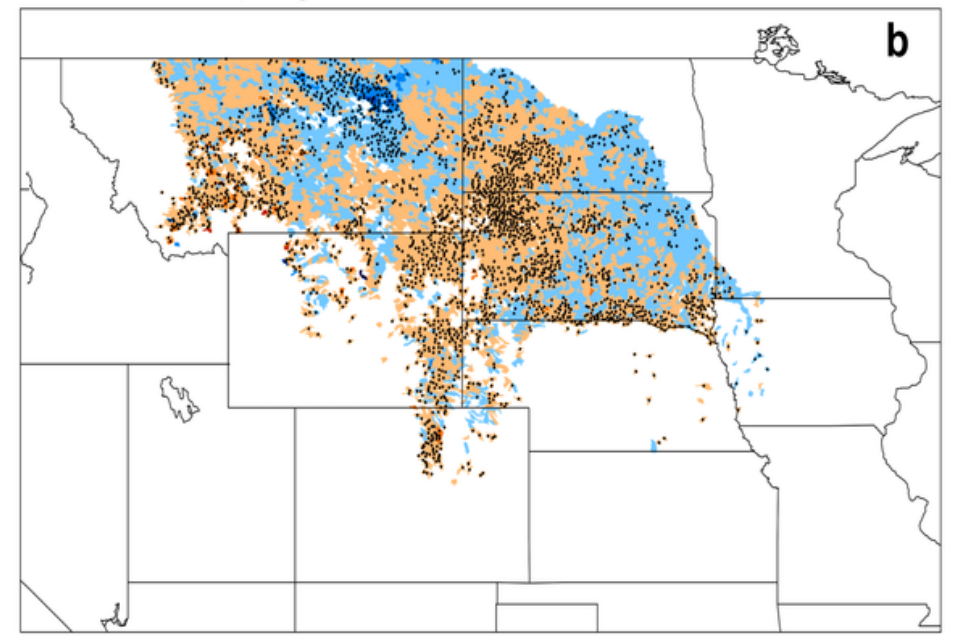

Winter Wheat $\mathrm{P}+\mathrm{T}-\mathrm{W}+$

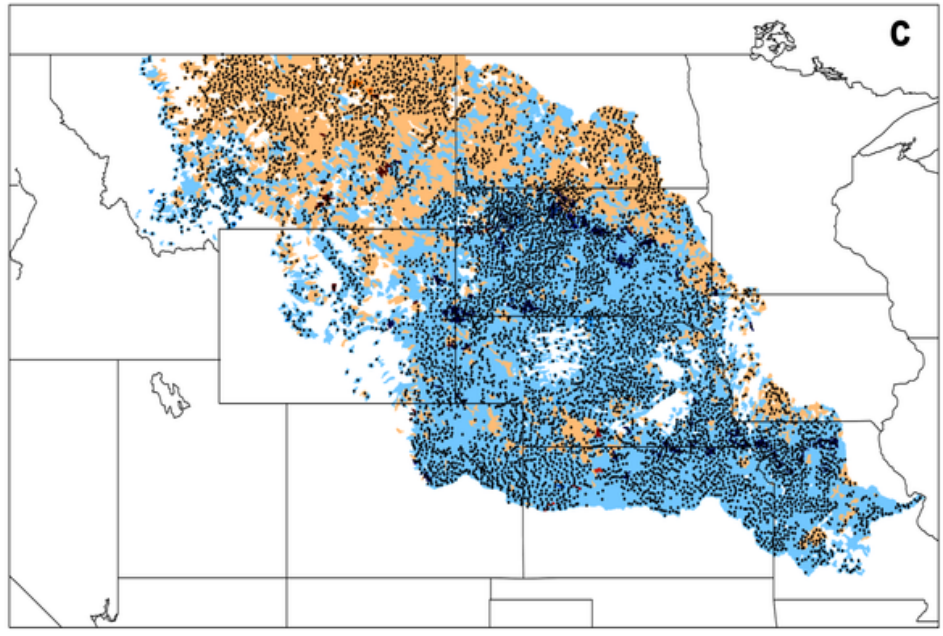

Winter Wheat P-T+W+

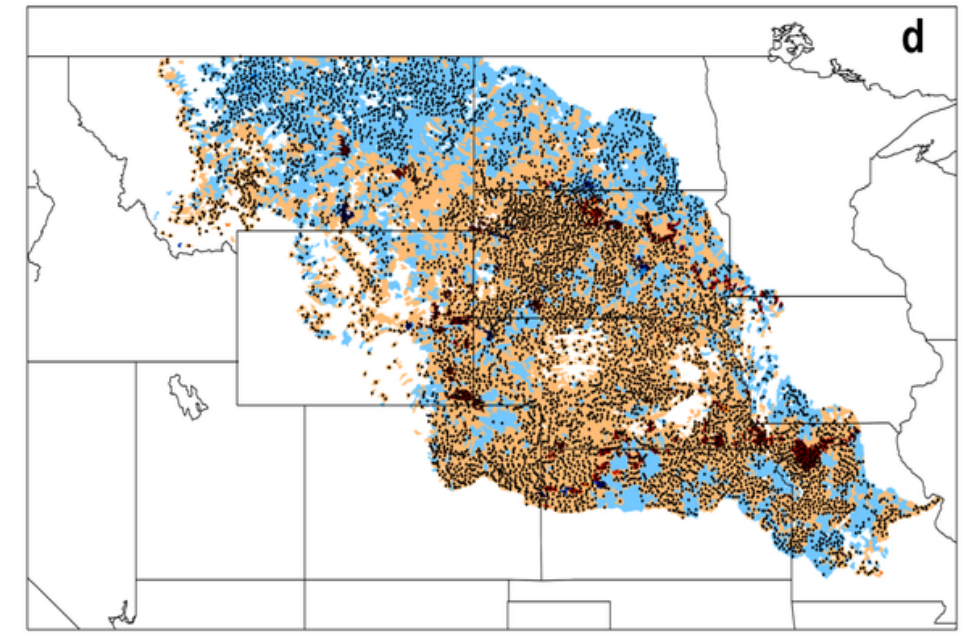

(n)

$\begin{array}{llll}10 & 20 & 30 & 40\end{array}$

Figure 5

SWAT-simulated annual-average spring and winter wheat yields (\% change from baseline) in the MRB in CDS-Averageg scenarios. (a) Spring wheat, PDO+, TAG-, WPWP+; (b) spring wheat, PDO-, TAG+, WPWP+; (c) winter wheat, PDO+, TAG-, WPWP+; (d) winter wheat, PDO-, TAG+, WPWP+. Black dots show locations of $95 \%$ significance. 


\section{Average DCV Amplitude}

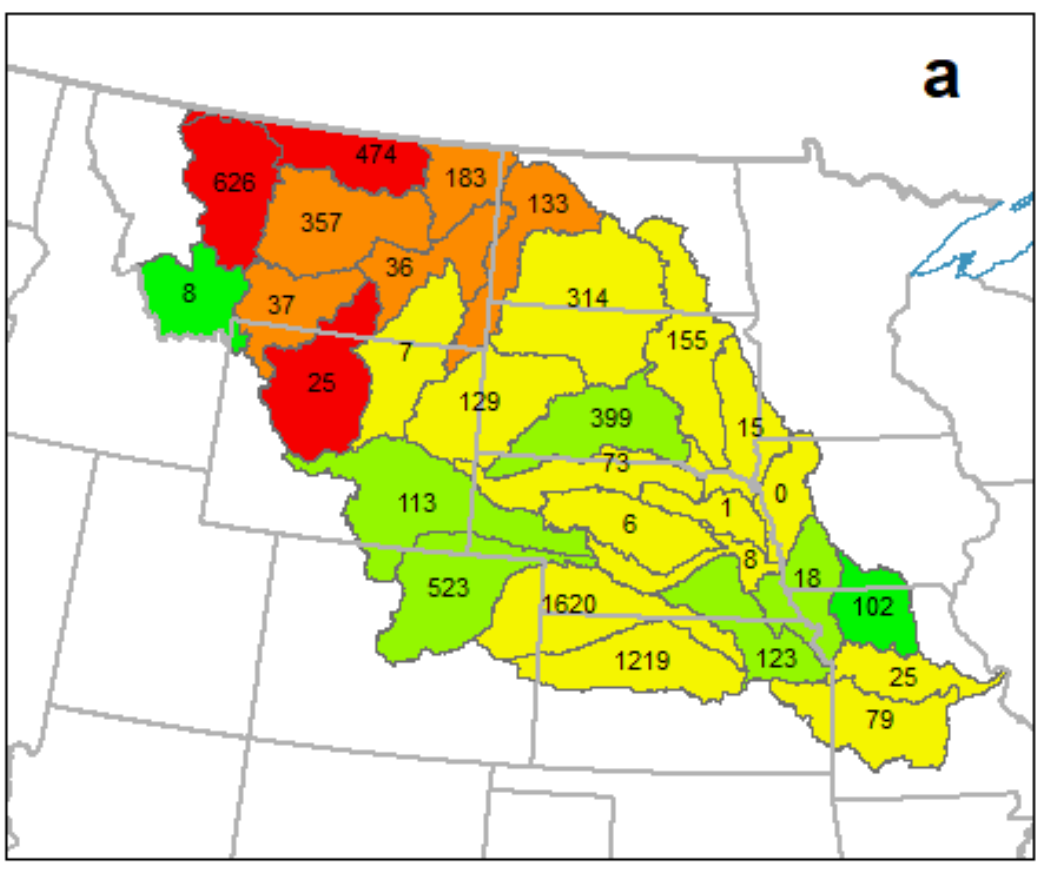

Extreme DCV Amplitude

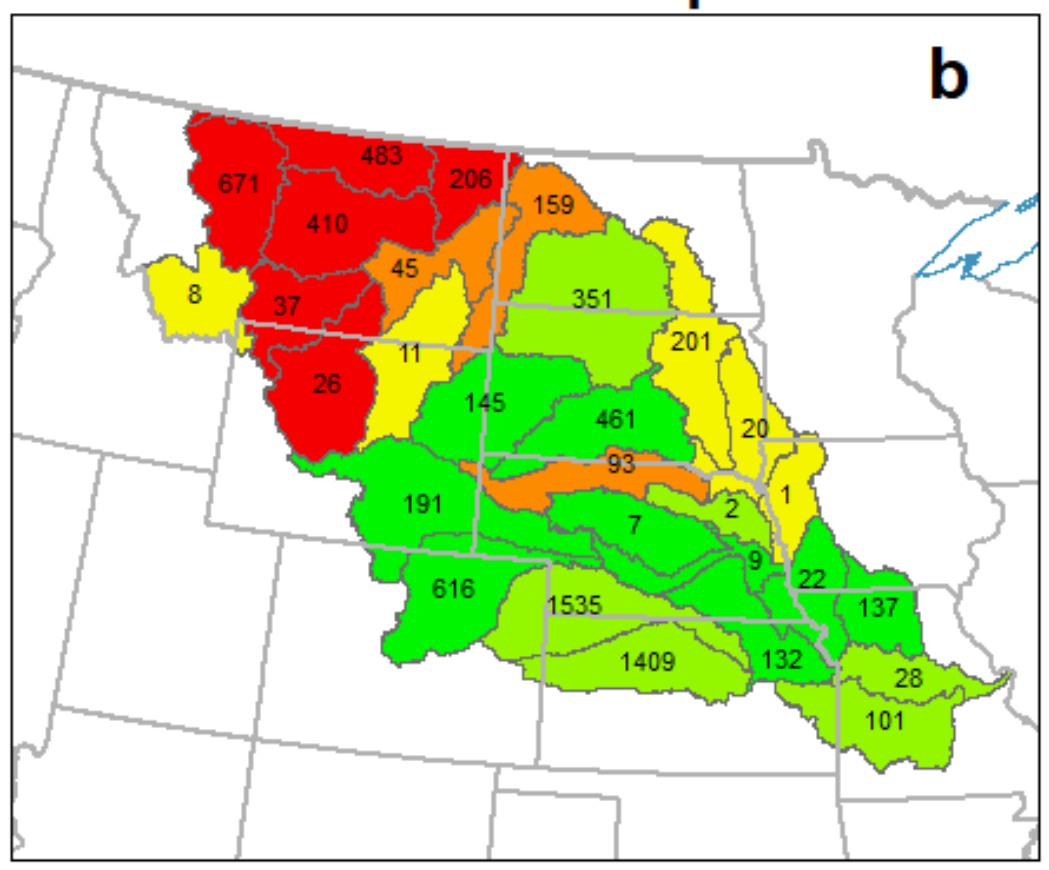

\section{Percent Change from} Average Production

\begin{tabular}{|l}
\hline-72 to -10 \\
-9 to 0 \\
\hline 1 to 10 \\
11 to 20 \\
21 to 59
\end{tabular}

\section{Figure 6}

SWAT-simulated, average winter wheat production (numbers in thousand metric tons) in 4-digit subbasins in the MRB in the two CDS-Average scenarios and the two CDS-Extreme scenarios. Shading shows the percent change from the simulated average production (numbers in each 4-digit sub-basin) of the difference between the two combined phases of (a) CDS-Average (Figs. $5 \mathrm{c}$ and 5d), and (b) CDS-Extreme scenarios. 


\section{Supplementary Files}

This is a list of supplementary files associated with this preprint. Click to download.

- OnlineResource1.docx

- OnlineResource2.docx 